\title{
Modelo Computacional Aplicado al Comportamiento de Agentes Financieros Mediante Autómatas Celulares (Cell-DEVS)i
}

\section{Computational Model Applied to the Behavior of Financial Agents Using Cellular Automata (Cell-DEVS)}

\author{
Jesús Barrantes Limahuaya ${ }^{2}$ \\ Neisser Pino Romero ${ }^{3}$ \\ Gabriel Wainer ${ }^{4}$
}

\begin{abstract}
RESUMEN
En el presente trabajo se realizará la simulación el efecto de la interdependencia y el contagio en las decisiones de compra y venta de los inversionistasen un mercado financiero de tipo Black-Schole,donde existen dos activos financieros: acciones (activo riesgoso) y bonos (activo libre de riesgo); y dos estados del inversionista: amante y averso al riesgo; bajo distintas probabilidades de contagio. Este fenómeno económico-financiero podría ser modelado por un sistema de ecuaciones estocásti-
\end{abstract}

1 Artículo con fines netamente académicos.

2 Analista del área de Finanzas Cuantitativas en Tail Risk Consulting. Responsable de la proyección de variables financieras para la plataforma Bloomberg.

Email: jbarrantes@tailrisk.pe, jbarrantesli@bloomberg.net

3 Docente de la Universidad Nacional Mayor de San Marcos, Facultad de Ciencias Económicas. Lima, Perú. Docente de la Facultad de Ciencias y Filosofía de la Universidad Peruana Cayetano Heredia. Docente de la Facultad de Ciencias de la Universidad Tecnológica del Perú.

Email: neisser.pino@unmsm.edu.pe,neisser.pino@upch.pe

4 Profesor y Director Asociado de Estudios de Postgrado. Departamento de Ingeniería de Sistemas y Computación, Carleton University (Canada's Capital University).

Email: gwainer@sce.carleton.ca

(C) Los autores. Este artículo es publicado por Pensamiento Crítico de la Facultad de Ciencias Económicas, Universidad Nacional Mayor de San Marcos. Este es un artículo de acceso abierto, distribuido bajo los términos de la licencia Creative Commons Atribucion - No Comercia_Compartir Igual 4.0 Internacional. (http:// creativecommons.org/licenses/by-nc-sa/4.0/) que permite el uso no comercial, distribución y reproducción en cualquier medio, siempre que la obra original sea debidamente citada. 
cas; sin embargo, no todas las ecuaciones estocásticas tienen una solución cerrada por lo que se opta por realizar simulaciones computacionales para analizar su comportamiento numérico, en este sentido, se realizará una simulación computacional mediante los autómatas celulares.

Palabras clave: Activo financiero; riesgo; interdependencia; contagio financiero; epidemiologia matemática; simulación computacional; autómatas celulares.

JEL: C6

\section{ABSTRACT}

In the present paper, the effect of interdependence and contagion will be performed in the purchase and sale decisions of investors in a Black-Schole financial market, where there are two financial assets: stocks (risky assets) and bonds (risk-free asset); and two investor states: lover and risk aversion; under different probabilities of contagion. This economic-financial phenomenon could be modeled by a system of stochastic equations; however, not all stochastic equations have a closed solution, so it is decided to perform computational simulations to analyze their numerical behavior. In this sense, a computational simulation will be performed using cellular automata.

Keywords: Financial assets; risk; interdependence; financial contagion; mathematical epidemiology; computer simulation; cellular automata.

JEL: C6

\section{Introducción}

Después de la crisis financiera internacional del 2008, que estalló en los Estado Unidos, surge la necesidad de estudiar la vinculación de las variables macroeconómicas y financieras con la finalidad de explicar los efectos del shock financiero en el sector real de la economía y viceversa.Parodi (2017) indica que esta crisis adquirió dimensiones globales; a su vez,el alcance mundial y los impactos sincronizados en los niveles de actividad económica, comercio internacional y flujo de capitales han generado comparaciones con la Gran Depresión de la década de 1930.

Cabe indicar que son las variables financieras las que presentan una fuerte volatilidad, esto se produce como resultado del conjunto de decisiones que toman los agentes financieros en función de sus expectativas del mercado.Estas expectativas dependen del conjunto de información actual y relevante, entre ellas las decisiones de compra y/o 
venta del activo por parte de los demás agentes que se encuentran en el mercado financiero.Parodi (2017) indica que los sistemas financieros son intensos en información; así, una crisis financiera está relacionada con problemas agudos de información entre las partes de una transacción financiera.

En el presente trabajo se simula el efecto de la interdependencia y el contagio en las decisiones de compra y venta de los inversionistasen un mercado donde existen dos activos financieros: acciones y bonos. Una acción es el instrumento financiero más básico, es la posesión de una pequeña parte de una compañía; su precio está determinado por un proceso aleatorio cuyas fluctuaciones pueden ser ocasionalmente muy profundas y depende de la situación financiera de la compañía que las ha emitido. Mientras, el bono es un compromiso de deuda que son emitidos por el Estado o por las corporaciones; es la inversión que proporciona un rendimiento en forma de pagos periódicos fijos y la eventual devolución del capital al vencimiento. Los bonos sirven como "refugio" ante períodos de fuerte volatilidad.

Este fenómeno económico-financiero podría ser modelado por un sistema de ecuaciones estocásticas. Otra área que permitiría obtener una concepción más interesante sería la metodología empleada para explicar el contagio epidemiológico. Esto quiere decir, que los modelos matemáticos comportamentales aplicados a la Epidemiologia donde se describe epidemias, transmisión de enfermedades infecciosas, la interacción entre las personas desarrollará la evolución del comportamiento del estado de las personas (Susceptibles, Expuestos, Infectados), esto permitiría que, a través del tiempo, se puede analizar el comportamiento que se realiza con respecto a las tasas epidemiológicas consideradas.

Pero este tipo de modelamiento también tiene sus limitaciones, por lo cual se relacionará con el modelamiento computacional mediante los Autómatas Celulares (A.C.) que esta técnica computacional que permite realizar simulaciones computacionales considerando el tiempo y espacio, con un complemento adecuado que permite visualizar la interacción de las personas mediante la interdependencia entre las personas que se rodean entre sí, y dependiendo de esta interacción se realizará el cambio de estado de las personas. 


\section{Marco Teórico}

\subsection{El modelamiento matemático aplicado a las Finanzas}

Hay diferentes maneras de representar los problemas económicofinanciero que se pueden observar en un mercado. Para nuestro caso, una primera forma de modelar un activo financiero es utilizando procesos estocásticos. Sea $S_{t}$ el precio de un activo al tiempo t; por lo tanto, el rendimiento del activo $R_{t}$ es:

$$
R_{t}=\frac{S_{t}-S_{t-1}}{S_{t-1}}
$$

Esto se puede estandarizar a una Normal con media cero y varianza uno:

$$
\frac{R_{t}-\mu}{\sigma}=z_{t}
$$

Donde $\mu$ es el rendimiento promedio y $\sigma$ es su desviación estándar. Despejando tenemos la siguiente expresión:

$$
R_{t}=\mu+\sigma z_{t}
$$

Ahora reemplazamos de la definición anterior expresada en la ecuación (1):

$$
\begin{gathered}
\frac{S_{t}-S_{t-1}}{S_{t-1}}=\mu+\sigma z_{t} \\
S_{t}-S_{t-1}=\mu S_{t-1}+\sigma S_{t-1} z_{t}
\end{gathered}
$$

Teniendo en cuenta el cambio en el tiempo, se tiene la siguiente ecuación:

$$
S_{t}-S_{t-1}=\mu S_{t-1} d t+\sigma S_{t-1} z_{t} \sqrt{d t}
$$

Esta ecuación es un Movimiento Browniano Geométrico (MBG), donde dt es el incremento del tiempo correspondiente al horizonte intra- 
recorrido entre t y $\mathrm{t}-1, \mu$ es el rendimiento promedio y $\sigma$ su desviación estándar.

En este sentido, a medida de ejemplo, describamos el comportamiento del precio de las acciones de Microsoft. En el gráfico $\mathrm{N}^{\circ} 1$ se puede apreciar que esta serie tiene un comportamiento estocástico, cuya media, varianza y tendencia de la serie son cambiantes en el tiempo. En el Gráfico $\mathrm{N}^{\circ} 1$ se presenta la evolución del precio de este activo financiero.

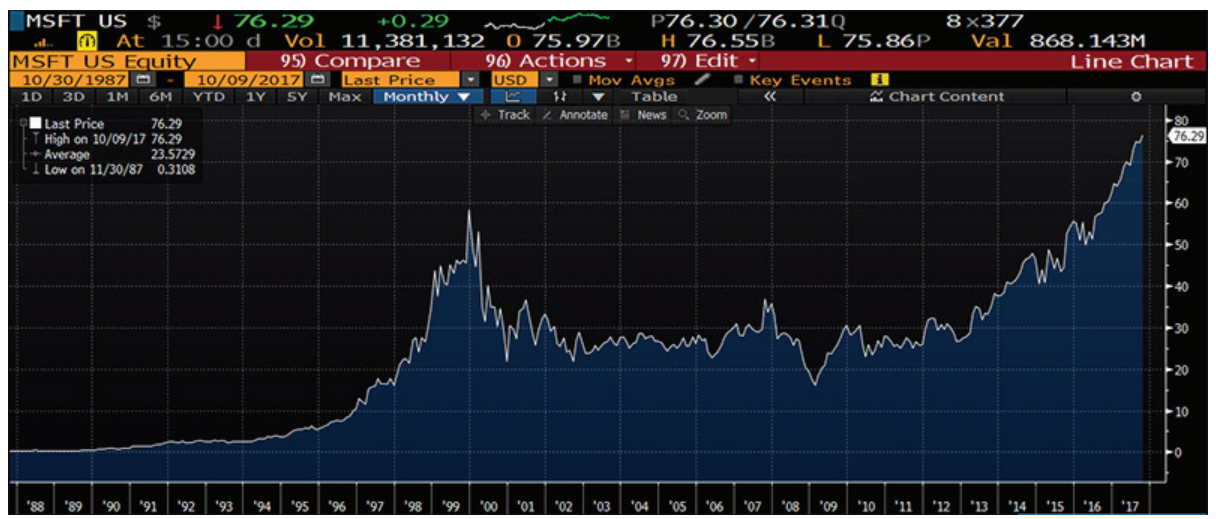

Gráfico $N^{\circ}$ 1. Evolución del precio de la acción de Microsoft US

Fuente: Bloomberg.

Esta serie presenta cambios en su tendencia a lo largo del horizonte temporal de análisis. Es positiva hasta el año 1999; negativa del 2000 al 2002; sin pendiente marcada, del 2003 al 2012; y nuevamente positiva del 2013 al 2017. A su vez presenta quiebre en media durante el periodo de la crisis financiera, del 2008 al 2009. Los cambios registrados con alta frecuencia es la volatilidad de la serie y es diferente período a periodo. Esto puede ser modelado como un Movimiento Browniano Geométrico (Ratanov, 2009).

Se considera un mercado financiero de tipo Black-Schole donde existen los dos activos ya definidos: acciones (activo riesgoso) y bonos (libre de riesgo). En este mercado financiero, el inversionista tiene la libertad de elegir entre cualquiera de estos activos, su elección está determinada por sus expectativas; es decir, el inversionista decide en que momento migrar de tener un activo riesgoso (acciones) a refugiarse 
en un activo libre de riesgo (bonos) y viceversa. Así, si el inversionista decide comprar acciones, su beneficio $\pi_{t}$ estará en función del precio de este activo, $\mathrm{f}\left(\mathrm{S}_{\mathrm{t}}\right)$ y este precio sigue un proceso estocástico. $\mathrm{Y}$, si decide comprar bonos, estará en función del precio del bono, el cual ofrece como retorno una tasa de interés fija r.Entonces, la función de beneficio del inversionista es el siguiente:

$$
\pi_{t}=\left\{\begin{array}{c}
f\left(S_{t}\right)=f\left(\mu S_{t-1} d t+\sigma S_{t-1} z_{t} \sqrt{d t}\right) ; \text { si elige acciones }(S) . \\
f\left(B_{t}\right)=f\left((1+r) B_{t-1} d t\right) ; \text { si elige bonos }(B) .
\end{array}\right.
$$

El hecho de que el inversionista se encuentre comprando acciones o bonos depende del estado en que se encuentre. Se define un estado amante al riesgo como aquel estado en el que el inversionista está dispuesto a asumir un nivel de riesgo relativamente alto y es por ello por lo que decide comprar acciones en búsqueda de mayor rentabilidad. Por otro lado, se define el estado averso al riesgo como aquel en el cual el agente no está dispuesto a tolerar un nivel de riesgo relativamente alto. El inversionista puede pasar de un estado amante al riesgo a estado averso al riesgo toda vez que sale a vender acciones y se refugia en un activo seguro (bonos).

Se plantea que existe una probabilidad de transición del estado amante al estado averso, esta es la probabilidad de contagio está definida de la siguiente manera:

$$
P\left(X_{n}=j \mid X_{n-1}=i\right)
$$

Donde la probabilidad de que uno se encuentre en el estado actual, $X_{n}=j$, sólo depende del estado inmediatamente anterior del sistema, $X_{n-1}=i$, mas no del tiempo en que se encuentra. Esto se conoce como una cadena de Markov homogénea(Wilmott, 2007). La probabilidad de contagio $p_{i j}$, ir del estado i al estado j en es:

$$
p_{i j}=P\left(X_{n}=j \mid X_{n-1}=i\right),
$$

Donde $\mathrm{i}, \mathrm{j}=$ amante al riesgo, averso al riesgo.

Ahora, una vez definido la función de beneficio del inversionista, ecuación 7, el problema es maximizar esta función. Cabe indicar que la ecuación que describe el comportamiento del precio de la acción, en este 
ejemplo, es una ecuación estocástica sencilla cuya solución cerrada es fácil de encontrar; sin embargo, no todas las ecuaciones estocásticas tienen una solución cerrada(Wilmott, 2007). En este caso se tiene que realizar simulaciones Monte-Carlo para encontrar una solución aproximada.

Otra forma de modelar un fenómeno económico-financiero es mediante un sistema de ecuaciones dinámicas. Desde esta perspectiva, los métodos numéricos realizan un gran trabajo para desarrollar sistemas dinámicos, como en este caso el desarrollo de un sistema de ecuaciones diferenciales; pero no siempre es accesible al tratamiento de los datos adecuadamente dependiendo la complejidad del sistema estudiado. Por lo cual, para auxiliar a ambos enfoques, es de mucho respaldo el estudio y simulación de sistemas dinámicos, intentando evitar las desventajas existentes en la matemática clásica para expresar la complejidad de estos sistemas. Es por eso por lo que se recurre a un método de modelización conocido como autómatas celulares (AC).

\subsection{El modelo matemático epidemiológico SEI - SEIS}

En 1927, W. O. Kermack y A. G. McKendrick propusieron un modelo matemático que intentaba describir el comportamiento de las enfermedades infecciosas, de donde se basó Cappaso y Serio (1978) para poder intentar generalizar el modelo matemático. El modelo tuvo la primera consideración desarrollarla mediante las Ecuaciones Diferenciales Ordinarias (E.D.O.), en su tiempo fue un gran aporte que realizo la matemática en cuanto al estudio de las epidemias. Desde ahí, se comenzó a recurrir al modelamiento matemático para intentar describir diferentes fenómenos en el área de la salud y la física. El modelo matemático SEI considera tres poblaciones epidemiológicas: Susceptibles (S), Expuestos (E) e Infectados (I). Y con las tasas epidemiológicas: tasa de contagio $(\beta)$ y la tasa de incubación $(\rho)$.

Se tiene que tener en cuenta que la población total del modelo es constante, es decir, no aumenta ni disminuye en el tiempo. Desde aquí, se propusieron diferentes enfoques a este modelo determinístico aplicado a las epidemias en las distintas poblaciones, como lo explicaron en su momento Anderson (1982) y de manera más actual Brauer y CastilloChávez (2001) para poder relacionarlas a diferentes problemáticas, no solamente epidemiológicas, sino también económicas. 
El modelo matemático epidemiológico SEI sería el siguiente:

$$
\begin{array}{ccc}
S^{\prime}(t) & = & -\beta S I \\
E(t) & = & \beta S I-\rho \mathrm{E} \\
I(t) & = & \rho \mathrm{E}
\end{array}
$$

Este modelo matemático representado en la ecuación (10), que pertenece a un sistema No lineal permitió en su momento una adecuada representación de la propagación de la epidemia que afectaba la sociedad. Actualmente, se ha desarrollado modelos matemáticos más complejos que intentan predecir situaciones que puedan suscitarse en la sociedad ante alguna enfermedad infecciosa. Para la simulación computacional se considerarálas siguientes poblaciones iniciales. Ylas tasas epidemiológicas normalizadas. Las tasas epidemiológicas han sido recogidas y modificadas para un acondicionamiento del estudio estadístico realizado por la Dirección General de Epidemiologia (DGE) y el Instituto Nacional de Estadística e Informática para un sector pequeño, enfocado al estudio de la transmisión de la influenza. Otro trabajo de investigación que se realizó por parte del Ministerio de Salud en el 2015 fue el libro de "Nociones Básicas de Modelamiento Matemático a la Epidemiologia"donde también recoge las tasas epidemiológicas consideradas para las simulaciones computacionales que se desarrollará. El motivo de este enfoque es debido que mediante el contacto de una persona que contrae la enfermedad, las personas susceptibles mantienen un periodo de latencia y pasan a ser infectadas, donde la consideración inicial es que permanecen con la enfermedad por siempre, esta misma dinámica se presenta entre las relaciones entre los inversionistas cuando analizan en un instante la acción ante la compra de una acción en la bolsa o mantenerse al margen.

Las poblaciones consideradas están consideradas en cientos, por mientras que las tasas epidemiológicas están normalizadas y expresadas unidad de persona por semana.

Poblaciones $\quad: \quad S(0)=98 \quad E(0)=0 \quad I(0)=2$

Tasas Epidemiológicas: $\quad \beta=0.45 \quad \rho=0.20$ 
La simulación será representada en cientos de personas y el tiempo en semanas. En esta simulación computacional es realizada por los métodos numéricos para poder aproximar las soluciones del sistema expresado en (10).

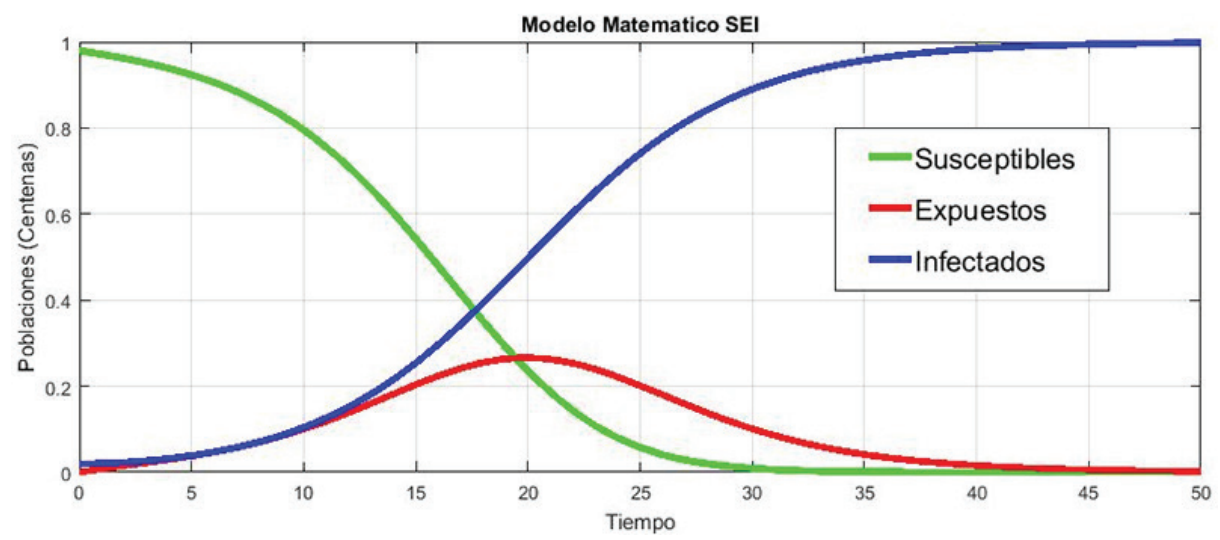

Gráfico $N^{\circ}$ 2. Modelo Matemático SEI

Fuente: Elaboración propia.

La simulación computacional nos permite analizar comolainteracción entre las poblaciones epidemiológicas se va desarrollando a través del tiempo. Ahora la evolución de cada población epidemiológica se basa en el contacto que tienen las personas susceptibles con las infectadas, para luego pasar a un periodo de incubación de la enfermedad, este estado de periodo latente permite un lapso de tiempo en que los nuevos infectados no pueden contagiar a otros susceptibles hasta que termine el periodo de incubación. Y como el modelo considera que cuando contraes la enfermedad te mantienes con ella a través del tiempo.

Si añadimos una consideración al modelo anterior (10), donde los Infectados después de un tiempo vuelven a ser Susceptibles bajo una tasa de recuperación $(\varphi)$. Al aplicar este hecho, el modelo matemático epidemiológico SEI se convierte en un modelo matemático epidemiológico SEIS.

Donde la presente consideración permite obtener un mejor modelamiento al problema que se presentará en la dinámica que existe 
entre los inversionistas. El proceso de ir paso a paso en el modelamiento matemático aplicado a la epidemiologia como también a la economía, es ir construyendo poco a poco mediante las consideraciones que representa la realidad del problema.

De esta consideración, el modelo matemático expresado en la ecuación (10) ha sido perturbado de la siguiente manera donde se ha añadido la última consideración.

$$
\begin{aligned}
S^{\prime}(t) & =-\beta S \mathrm{I}+\varphi \mathrm{I} \\
E(t) & =\beta \mathrm{SI}-\rho \mathrm{E} \\
I(t) & =\rho \mathrm{E}-\varphi \mathrm{I}
\end{aligned}
$$

Del mismo anterior, se considerará las poblaciones iniciales y las tasas epidemiológicas respectivas donde se incluirá la tasa de recuperación $(\varphi)$, incluida en la base de datos de la Dirección General de Epidemiologia (DGE).

$$
\begin{array}{lll}
S(0)=98 & E(0)=0 & I(0)=2 \\
& \beta=0.45 & \rho=0.20 \varphi=0.30
\end{array}
$$

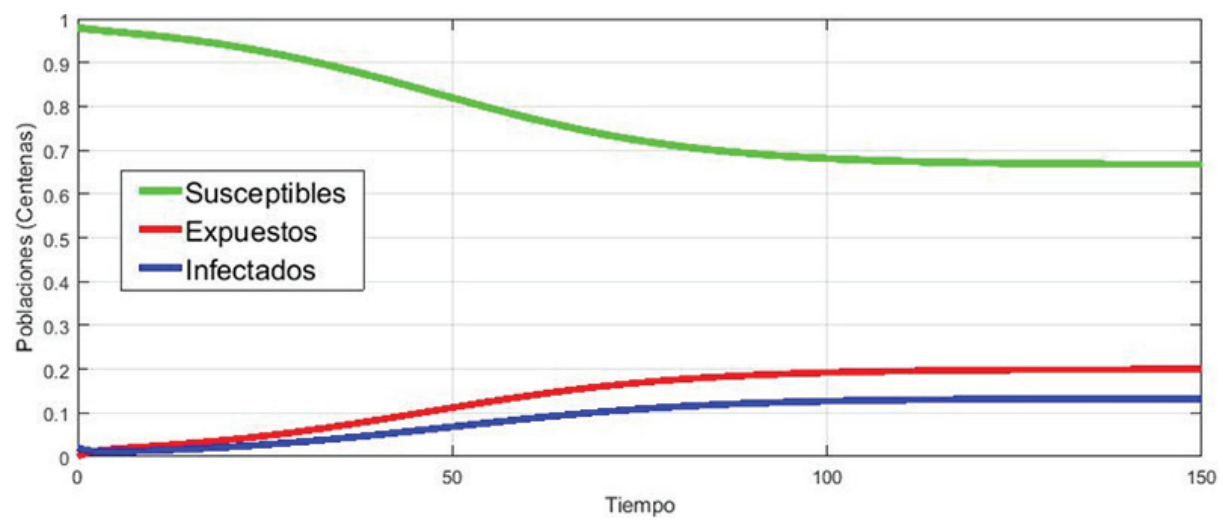

Gráfico $N^{\circ}$ 3. Modelo Matemático SEIS

Fuente: Elaboración propia.

Esta última simulación computacional se ha considerado 150 días debido que la interacción que existe entre las poblaciones epidemiológicas 
se viene dando de una forma que no pareciera un cambio significativo dentro de sus poblaciones totales respectivas. Por lo cual esta simulación computacional no nos permite visualizar el cambio que hay entre cada población al interactuar con las otras. De aquí, la simulación del Modelo SEIS no permitiría una adecuada interpretación para nuestra problemática económica.

Por lo cual, entraremos a otra forma de generar simulaciones computacionales que son los Autómatas Celulares. Más aun cuando se está considerando la perspectiva de contagio financiero ante situaciones donde las personas deben tomar decisiones significativas. Estas decisiones se tienen que visualizar notablemente para poder realizar un análisis detallado con una visión de percepción económica y generar predicciones adecuadas.

Como también lo ha expresado Morales (2015) en su investigación,donde su trabajo se basó a un análisis más detallado de las diferentes interacciones en América Latina, generando la denominación de "contagio financiero e interdependencia" entre inversionistasdonde se puede generar una relación entre el modelamiento epidemiológico y el modelamiento económico, de manera particular enfocado a las finanzas. Cabe mencionar, que se ha considerado el modelamiento mediante las Ecuaciones Diferenciales Ordinarias para describir la evolución de las poblaciones consideradas a través del tiempo (única variable independiente), por lo cual un adecuado modelamiento mediante las Ecuaciones Diferenciales seria las Ecuaciones Diferenciales Parciales, este tipo no se considerara en el presente trabajo de investigación.

\subsection{Los Autómatas Celulares}

La técnica de modelado mediante los Autómatas Celulares permite mantener la capacidad para describir sistemas complejos utilizando reglas muy sencillas. Los autómatas celulares (A.C.) surgen en la década de 1940 con John Von Neumann, el cual intentaba modelar una máquina que fuera capaz de auto replicarse, llegando así a un modelo matemático con reglas complicadas sobre una red rectangular, esto nos indica la introducción del libro de Gabriel Wainercomo también los trabajos de investigación de Toffoli y Zeiglerpara poder realizar una adecuada concepción computacional de la finalidad de los autómatas celulares. 
Por lo cual, un Autómata Celular es un Modelo Matemático para un Sistema Dinámico, conformado por un conjunto de celdas o células que adquieran distintos estados o valores. Estos estados son alterados de un instante a otro en unidades de tiempo discreto, es decir, que se puede cuantificar con valores enteros a intervalos regulares. De esta manera, este conjunto de células logra una evolución (efecto contagio) según una determinada expresión matemática, que es sensible a los estados de las células vecinas (efecto interdependencia), la cual se le denomina reglas de transición local.

La definición de un Autómata Celular requiere mencionar sus elementos básicos, para considerar formalmente las reglas que se puedan representar ante un sistema dinámico.

- Arreglo Regular: Sea un plano bidimensional o un espacio n-dimensional, este es el espacio de evoluciones considerado, y cada división homogénea de arreglo es llamada célula.

- Conjunto de Estados: Es finito y cada célula del arreglo toma un valor de este conjunto de estados. Las células pueden ser expresados en valores o colores.

- Configuración Inicial: Es la asignación de un estado a cada célula del espacio de evolución inicial del sistema.

- Vecindades: Es el conjunto contiguo de células y posición relativa respecto a cada una de ellas. A cada vecindad diferente corresponde un elemento del conjunto de estados.

- Función Local: Es la regla de evolución que determina el comportamiento del A.C. Se conforma de una célula central y sus vecindades. Define como debe cambiar de estado cada célula dependiendo de los estados anteriores de sus vecindades obedeciendo las reglas definidas que pueden ser una expresión algebraica o un grupo de ecuaciones.

Si bien esta técnica nos permite describir sistemas complejos utilizando reglas muy sencillas, existen inconvenientes y complicaciones debido a que la estructura del sistema no resulta evidente o sencillo de representar y/o el fenómeno al cual se está estudiando se encuentra en 
proceso de investigación. A su vez, suponiendo que se logra obtener la representación matemática mediante las Ecuaciones Diferenciales u otra expresiones de Ecuaciones que representan al sistema, los problemas surgen cuando hay que analizar el sistema mediante los métodos analíticos para describir el comportamiento de las soluciones, o también por los métodos numéricos, donde se requiere de computadoras con gran cantidad de memoria y velocidad de procesamiento de datos durante tiempos prolongados para obtener una solución numérica que permita realizar interpretaciones adecuadas al fenómeno que se está modelando. Finalmente, resulta difícil y en muchos casos complicado realizar una interpretación del modelo simulado sea aproximado de lo que se ha deducido directamente de la observación de los fenómenos naturales.

\subsection{El formalismo DEVS y los modelos atómicos en Cell-DEVS}

Se han utilizado diferentes formalismos para describir el comportamiento de diversos sistemas que pueden ser representados por los Espacios Celulares (por ejemplo, modelos espaciales en los que el espacio en estudio se organiza como una cuadrícula de células distribuidas geométricamente). Ejemplos tan variados para los sistemas que se pueden encontrar en muchos campos de la naturaleza, desde la química a la ingeniería, y de la física a las ciencias sociales como es la Economía.

De aquí, es que se puede utilizar el formalismo DEVS. DEVS es el acrónimo de "DiscreteEventSystemSpecification" (Especificacion de Sistemas de Eventos Discretos). Con respecto a Cell-DEVS, es la Cell-DEVS es la combinación de los Autómatas Celulares (A.C.) y el formalismo DEVS. Cada célula está definida como un Modelo Atómico, y se determina el procedimiento para acoplar las células, es decir, se define la interacción de las células entre sí.

En la parte de las Ciencias Sociales, nos centraremos en la aplicación de un problema económico que afecta a la sociedad en cuanto a diversificación y dinamismos de los activos financieros. Los autómatas celulares son un formalismo conocido que describe estos tipos de sistemas. En la siguiente subsección se dará las algunas especificaciones formales para un Autómata Celular (A.C.), y al formalismo Cell-DEVS, que nos permite definir espacios basados en modelos DEVS y A.C. Con lo cual, 
podremos expresar nuestro modelo computacional aplicado a los agentes financieros con toda la formalidad que necesita un modelo mediante el formalismo Cell-DEVS.

\section{Modelo y simulaciones computacionales}

\subsection{El modelo computacional}

El modelo computacional expresado mediante las reglas pertinentes formalizado en DEVS será de vital importancia para la generación de la simulación computacional que nos permitirá analizar el comportamiento y la evolución de los agentes financieros. Dentro del formalismo DEVS se tiene que considerar todos los elementos de la estructura para que quede comprendido las diversas interacciones entre las células consideradas (agentes financieros) donde su siguiente estado depende de estas interacciones con las otras células, este proceso se describirá mediante los eventos discretos para cada célula.

Para la simulación computacional se considera que la célula central representa al agente que posee activos riesgosos, que al entrar en contacto con un agente que acaba de vender sus activos riesgosos, pasa a un estado de expectativa de ventay finalmente decide cambiar o no al estado donde vende todos sus activos;así de esta manera el agente sufre un efecto contagio producto del entorno financiero que lo rodea.

Ahora, los agentes que vendieron todo después de un tiempo, dependiendo de los que están a su alrededor puede mantenerse en ese mismo estado o pasar a comprar para poder regresar al estado de poseedor de activos. Esta breve y objetiva descripción de los agentes de cómo pasan a estar en otro estado dentro de la dinámica de la economía desde la perspectiva del contagio financiero, se tiene que formalizar mediante reglas estructuradas para generar el modelo computacional que se desarrollará mediante los autómatas celulares (Cell-DEVS).

Como se había mencionado sobre los elementos de un autómata celular, se mencionó el concepto de vecindad se relaciona al entorno que puede interactuar al centro de esta vecindad con sus alrededores, por lo cual ahora, se definirá de una manera más formal en su sentido matemático y 
en conjunto a la formalización de la función local respectiva que definirá sistemáticamente la interacción entre las células.

Según Muñoz Reyes y Wainer, se puedeformalizar una definición para el caso bidimensional de los autómatas celulares sobre $\mathbb{Z}^{2}$. Consideraremos $\theta_{n}=\{0 ; 1 ; 2 ; \cdots ; n-1\}$ siendo el conjunto de los posibles estados del autómata, es decir, se tiene que visualizar que en los en el plano cartesiano $\mathbb{Z}^{2}$, para este caso se considera $\mathrm{H}=\left[-a_{1}, b_{1}\right] \times\left[-a_{2}, b_{2},\right]$ donde se definirá una región rectangular, y donde se definirá la función (regla) local de la siguiente manera: $\Psi\left(\theta_{n}\right)^{H} \rightarrow \theta_{n}$.

De aquí, se denomina las vecindades de Moore y Neumann, donde son las más usadas en el modelamiento mediante autómatas celulares. En las siguientes graficas se mostrará la vecindad de radio uno y de radio dos, donde se puede realizar la generalización a un radio de longitud "n".
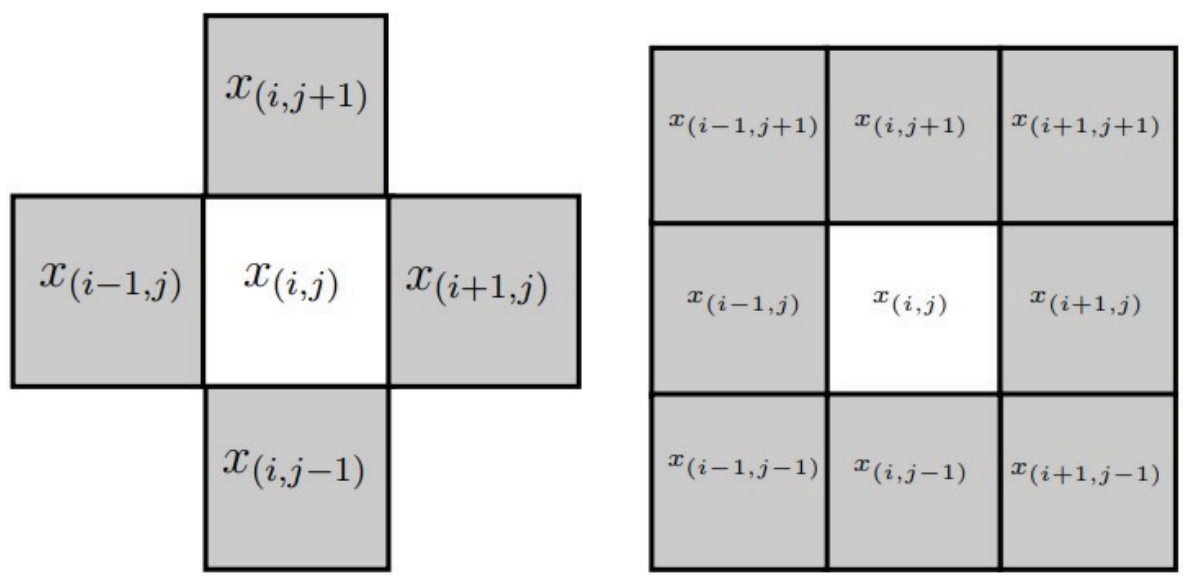

Gráfico $\boldsymbol{N}^{\circ}$ 4. Vecindad de Moore y Neumann (radio 1)

Fuente: Música con Autómatas Celulares (Ricardo Muñoz Reyes)

En el siguiente gráfico, se puede apreciar la segunda forma de una vecindad más amplia, todo esto depende del modelo matemático que se quiere formalizar ante una problemática real. 

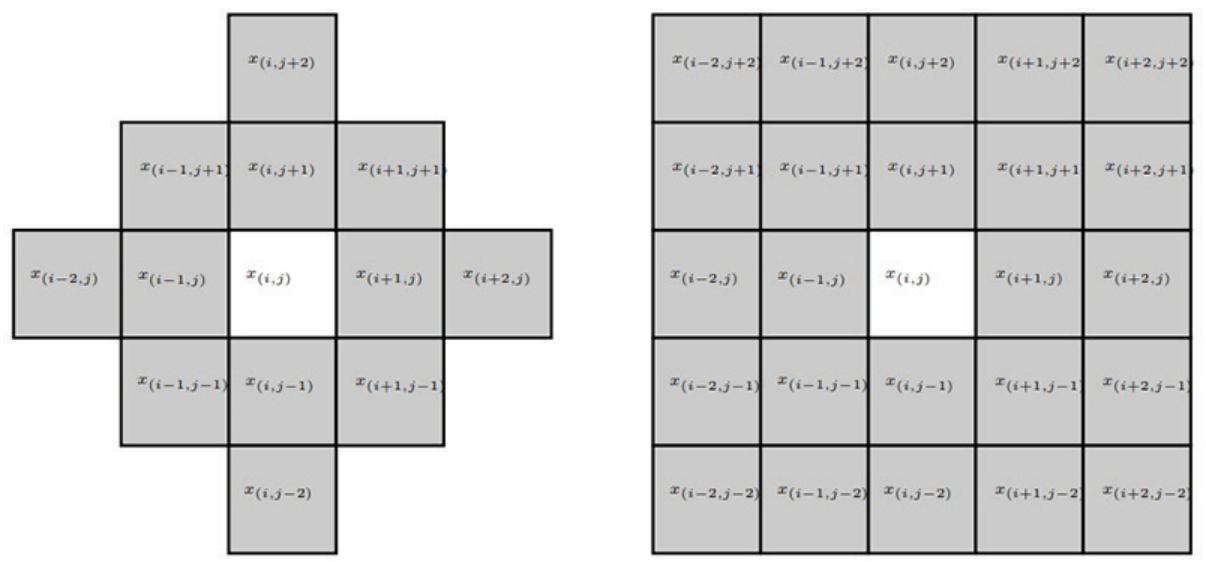

Gráfico $\boldsymbol{N}^{\circ} \mathbf{5}$. Vecindad de Moore y Neumann (radio 2)

Fuente: Música con Autómatas Celulares (Ricardo Muñoz Reyes)

A continuación, se presenta una malla rectangular (o también rectangular o también de una forma de romboide, o alguna región definida como se crea conveniente), esto quiere decir, que la malladonde se pueda representar las celdas que ocuparan un lugar en el espacio considerado donde se generara la interacción de células (personas).

La mayoría de los modelos computacionales se realiza mediante un mallado rectangular, esta técnica es realizada en las diversas áreas del modelamiento, por ejemplo en las Ecuaciones Diferenciales Parciales (E.D.P.) donde se considera el tiempo y el espaciocomo las variables independientes.

Estas dos variables serán de vital importancia para un adecuado modelamiento de un problema, tanto en las Ecuaciones Diferenciales como para los Autómatas Celulares (A.C.). En nuestro modelo se considerará la vecindad de tipo Neumann donde se presentará una mallarectangular (región) donde estarán las células (en sus diferentes estados) para poder interactuar entre ellas.

Las reglas que describirán el modelo económico mediante los autómatas celulares podrán ser formalizadas de tal manera que al representarlos en el respectivo algoritmo sea interpretado en $\mathrm{CD}++$ para realizar la respectiva simulación computacional. Hay que tener en cuenta 
que las consideraciones del modelo expresadas en la anterior subsección serán formalizadas de manera objetiva.

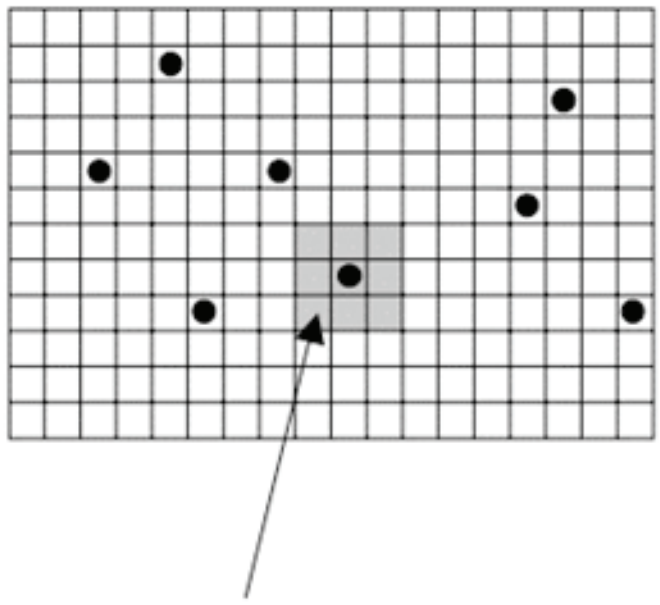

\section{Cell neighborhood}

Gráfico $N^{\circ}$ 6. Malla Rectangular (Región)

Fuente: Discrete Events Modelling and Simulation, A Practioner's Approach (G. Wainer)

Existen dos estados y un intermedio. La primera es el estado amante al riesgo en el cual el inversionista cuenta con los activos financieros riesgosos; la segunda, el estado averso al riesgo en el cual el inversionista vende todos sus activos riesgosos y compra bonos, esto también lo indica de manera Capinski y Zastawniak (2003) y lo expresa Morales (2015). Entre estos dos estados existe un intermedio, el cual es llamado como tiempo de expectativa, donde el inversionista evalúa su decisión de pasar o no al otro estado dado el comportamiento de los demás. Por lo cual, se puede describir la interacción de las acciones de los inversionistas (células) de la siguiente manera:

- El Inversionista con activos riesgosos (acciones) permanecen en el mismo estado (amante al riesgo) ante la ausencia de otros inversionistas que se encuentren en un estado diferente (averso al riesgo). 
- La interacción entre agentes que poseen activos riesgosos (acciones) y agentes que han vendido todo y en consecuencia tienen activos seguros (bonos) genera una expectativa de venta.

- En la expectativa de venta pasa un periodo latente antes de realizar la venta total del activo riesgoso (acciones).

- El agente financiero que ha vendido todos sus activos riesgosos se mantendrá en ese estado.

- Después de analizar la situación se puede considerar a volver a conseguir activos riesgosos (acciones), esto se generará ante la cantidad de inversionistas que consideren volver al estado inicial de amante al riesgo.

Las células o celdas, como se mencionó, están definida mediante números, donde éstas representan a los inversionistas dependiendo sus estados. De aquí, se va definir los estados de cada célula (inversionista).

$$
\text { Célula }=\left\{\begin{array}{c}
\text { Inversionista Con activos riesgosos (Valor 0) } \\
\text { Inversionista con Evaluación de cambio (Valor 1) } \\
\text { Inversionista Sin activos riesgosos (Valor 2) }
\end{array}\right.
$$

Las reglas que describen el comportamiento del inversionista se presentan en el siguiente cuadro.

\section{Tabla $\mathbf{N}^{\circ}$ 1. Reglas}

Estado Inicial de la Célula

Regla para que se Realice el cambio de Estado

$(2)=0 \quad y \#(1)=0$

$\#(2) \geq 1$

Prob_TiempoExpectativa

$\#(0) \geq \#(2)$ y Prob_Regreso

$\#(0) \leq \#(2)$ y Prob_Permanencia
Estado Final de la Célula

0

1

2

0

2

Fuente: Elaboración propia. 
Los colores de las celdas que corresponden a los resultados presentados en la tabla anterior son las siguientes:

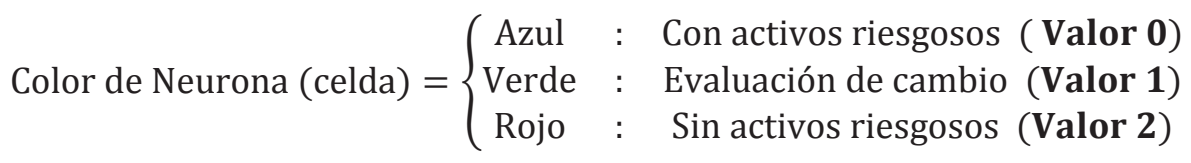

Un detalle significativo que las consideraciones enunciadas, tienen un parecido a las premisas del modelo matemático epidemiológico SEI de W. O. Kermack y A. G. McKendrick (1927), donde se modela la dinámica de transmisión de una enfermedad infecciosa en una población total constante, donde no se tiene en cuenta la natalidad ni la mortalidad de los individuos (sistema cerrado).

\subsubsection{Formalismo DEVS aplicado al Modelo Computacional}

Después de realizar las consideraciones necesarias para poder formalizar el modelo computacional sobre la dinámica del contagio financiero entre los tres agentes, dos principales y uno de transición, procederemos a presentar la formalización DEVS.

Enlos diferentes modelos matemáticos, se deben realizar elformalismo matemático para garantizar el adecuado funcionamiento de la interacción de las células como están descritos en el libro "DiscreteEventsModelling and Simulation, A Practioner'sApproach" y a la vez, expresado en el artículo "Modelamiento Computacional de la Dinámica de Transmisión de la Varicela mediante Autómatas Celulares (Cell-DEVS)."

Desde aquí, se puede presentar las debidas estructuras algebraicas para la construcción del modelo computacional.

Agente_Financiero $=<X, Y, D,\left\{M_{i}\right\},\left\{I_{i}\right\},\left\{Z_{i}\right\}$, select $>$

- $X=\varnothing$

- $Y=\varnothing$

- $D=\{$ cell $\}$

- $\quad M_{\text {cell }}=$ Cell_AgenteFinanciero

- $I_{\text {cell }}=\varnothing$

- $Z_{i}=\varnothing$

- $\quad$ select $=($ Cell_AgenteFinanciero $)$ 
Cell_AgenteFinanciero $=<X_{\text {list }}, Y_{\text {list }}, I, X, Y, n,\left\{t_{1}, t_{2}, \cdots, t_{n}\right\}, \eta, N, C, B, Z$, select $>$

- $X_{\text {list }}=\emptyset$

- $Y_{\text {list }}=\varnothing$

- $I=<p^{x}, p^{y}>$ donde: $p^{x}=p^{y}=\varnothing$

- $X=\{0,1,2\}$

- $n=2$

- $\eta=2$

- $\quad N=\{(-1,-1),(-1,0),(-1,1),(0,-1),(0,0),(0,1),(1,-1),(1,0),(1,1)\}$

- $B=\emptyset$

- $Z=\left\{P_{i, j} Y_{1} \rightarrow P_{i, j-1} X_{1}, P_{i, j} Y_{2} \rightarrow P_{i+1, j} X_{2}, P_{i, j} Y_{3} \rightarrow P_{i, j+1} X_{3}, P_{i, j} Y_{4} \rightarrow\right.$ $P_{i-1, j} X_{4}, P_{i, j} Y_{5} \rightarrow P_{i, j} X_{5}, P_{i, j+1} Y_{1} \rightarrow P_{i, j} X_{1}, P_{i-1, j} Y_{2} \rightarrow P_{i, j} X_{2}, P_{i, j-1} Y_{3} \rightarrow$ $\left.P_{i, j-1} X_{3}, P_{i+1, j} Y_{4} \rightarrow P_{i, j} X_{4}, P_{i, j} Y_{5} \rightarrow P_{i, j} X_{5}\right\}$

$$
\boldsymbol{C}_{i, j}=<, I, X, Y, N, \boldsymbol{\delta}_{\text {int }}, \boldsymbol{\delta}_{\text {ext }}, \boldsymbol{d}, \boldsymbol{\tau}, \lambda>
$$

- $X_{\text {list }}=\emptyset$

- $Y_{\text {list }}=\emptyset$

- $p^{x}=\left\{X_{k} \in\{0,1,2,3\}\right.$ donde $\left.k=\overline{1,9}\right\}$

- $p^{y}=\left\{X_{k} \in\{0,1,2,3\}\right.$ donde $\left.k=\overline{1,9}\right\}$

- $X=\{0,1,2\}$

- $Y=\{0.1 .2\}$

- $\quad N=\{(-1,-1),(-1,0),(-1,1),(0,-1),(0,0),(0,1),(1,-1),(1,0),(1,1)\}$

- $d=$ Tiempo(días)

- $S X:$ Variables Descriptivas

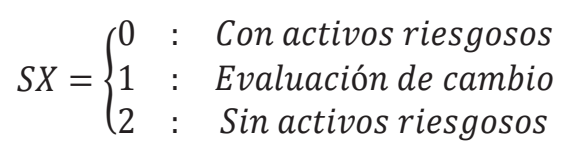

Ahora que ya tenemos el modelo, a continuación, pasamos a realizar las simulaciones. Las simulaciones computacionales nos permiten poder visualizar mejor la interacción de las células entre sí, esto conlleva un análisis computacional, cuando a la plataforma en donde se pueda realizar la programación y de que recursos computacionales se necesitan o requieren para obtener una buena simulación computacional. 


\subsection{La simulación computacional}

Antes de realizar la simulación computacional, mencionaremos sobre el programa que se empleó para las simulaciones. Hay diferentes softwares para realizar simulaciones computacionales de los diferentes sistemas dinámicos aplicados a la Economía (Matlab, Maple, Mathematica, RStudio, Python, C++, Java, etc). De la misma manera, para realizar las simulaciones computacionales con la perspectiva de los Autómatas Celulares se puede utilizar: Matlab, Mathemaica, Python, RStudio, Java, C++.

Para las simulaciones del presente documento se utilizó el programa $\mathrm{CD}++$, la razón principal es la facilidad de definir las reglas que contienen las consideraciones fundamentales que conforman el modelo propuesto. CD++ es un programa destinado a la modelización y a la simulación de eventos discretos cuales se organizan según el formalismo DEVS. CD++ puede funcionar en diferentes modos: en modo autónomo (soló un ordenador), en modo servidor, en modo tiempo real y en modo paralelo con un cluster Linux. CD++ se utiliza en línea de comandos;sin embargo, existe una interfaz gráfica llamada $\mathrm{CD}++$ Builder que funciona como un plugin para Eclipse. Donde CD++Builder permite a desarrolladores crear, editar o consultar proyectos de simulación CD++ en un entorno de desarrollo integrado (IDE).

Esta herramienta, accionado por Eclipse, ofrece un IDE en lo que podemos crear, obrar o grabar proyectos. Así ofrece muchas funcionalidades como un editor con sintaxis de colores. Es un soporte para editar archivos $\mathrm{C}++$. Permite importar y exportar datos. Además, el plugin contiene una interfaz gráfica de usuario para los instrumentos CD++.

\subsection{Las simulaciones computacionales}

De manera particular, se considera una malla de $10 \times 10$ que contiene una población total de 100 agentes en donde se considera un solo agente que ha vendido todo y los demás son agentes que poseen activos riesgosos. A partir de esta consideración inicial se procede realizar la simulación computacional para poder analizar cómo se desarrolla su evolución a través del tiempo de simulación considerado.

Por otro lado, se tiene en cuenta un tiempo de simulación de 50 minutos en el tiempo real, equivalente a un tiempo de simulación de 50 milisegundos. 
Se realizan tres simulaciones computacionales para tener tres diferentes escenarios con distinta probabilidad del contagio financiero.

\subsubsection{Estado inicial}

En punto de partida es aquel donde existe al menos un agente con la característica particular de que vendió todos sus activos riesgosos. Para una mejor ejemplificación de como la existencia de un solo inversionista distinto a los que hay en una sala.

Este ejemplo donde se ve claramente en una región donde se encuentra una persona infectada de una enfermedad contagiosa en medio de personas susceptibles que mediante el traspasar el tiempo, la persona infectada va contagiando a los demás, pero con el tiempo que traspasa las personas infectadas se van recuperando. Por lo cual, el enfoque de la dinámica de transmisión de una enfermedad infecciosa (epidemiologia matemática).

\begin{tabular}{|c|c|c|c|c|c|c|c|c|c|}
\hline$\theta$ & $\theta$ & $\theta$ & $\theta$ & $\theta$ & $\theta$ & $\theta$ & $\theta$ & $\theta$ & $\theta$ \\
\hline$\theta$ & $\theta$ & $\theta$ & $\theta$ & $a$ & $\theta$ & $\theta$ & $a$ & $\theta$ & $\theta$ \\
\hline 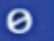 & $\theta$ & $\theta$ & $\theta$ & $\theta$ & $\theta$ & $\theta$ & 0 & 8 & $\theta$ \\
\hline$\theta$ & $\theta$ & $\theta$ & $\theta$ & $\theta$ & $\theta$ & $\theta$ & $\theta$ & $\theta$ & $\theta$ \\
\hline$\theta$ & $\theta$ & $\theta$ & $\theta$ & $\theta$ & $\theta$ & $\theta$ & $\theta$ & $\theta$ & $\theta$ \\
\hline$\theta$ & $\theta$ & $\theta$ & $\theta$ & $\theta$ & 2 & $\theta$ & $\theta$ & $\theta$ & $\theta$ \\
\hline$\theta$ & $\theta$ & $\theta$ & $\theta$ & 0 & 0 & 0 & 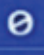 & 0 & $\theta$ \\
\hline ? & $\theta$ & $\theta$ & $\theta$ & $\theta$ & $\theta$ & $\theta$ & $\theta$ & $\theta$ & $\theta$ \\
\hline & 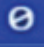 & $\boldsymbol{e}$ & $\theta$ & $\theta$ & $\theta$ & $\theta$ & $\theta$ & $\theta$ & $\theta$ \\
\hline & $\theta$ & $\theta$ & $\theta$ & $\theta$ & $\theta$ & $\theta$ & $\theta$ & $\theta$ & $\theta$ \\
\hline
\end{tabular}

Gráfico $N^{\circ} 7$. Estado Inicial

Fuente: Elaboración propia.

Como se había mencionado, la dinámica de interacción entre inversionistas en una sala cerrada (donde se ha considerado para la construcción del modelo) permite visualizar como se genera una epidemia de pasar de un estado a otro estado (de un inversionista con activos riesgosos a un estado de Evaluación de cambio y después a un inversionista sin activos riesgosos y desde aquí, evaluar su permanencia o su regreso al estado inicial). 
Por lo cual, en este sentido de una manera didáctica presentaremos el estado inicial y se realizará diferentes escenarios para poder realizar un adecuado análisis situacional ante diferentes perspectivas de cambio.

Los escenarios permiten conocer mejor el comportamiento de los agentes financieros bajo diversas situaciones. Estos resultados son de vital importancia para evaluar la capacidad de influencia del agente que vende sus activos riesgos en los demás agentes poseedores de los mismos y viceversa.

\subsubsection{Estado final: Escenario de simulación 1}

En el primer escenario de la simulación computacional se considera una probabilidad de contagio del 100\%. Dada esta probabilidad, la decisión del inversionista es vender todos sus activos riesgos.

El código mostrado anteriormente, representa las consideraciones para este primer escenario de la simulación computacional. Al realizar la simulación computacional en Cell-DEVS se obtendrá un historial de estados de los agentes financiero dentro de tiempo considerado.

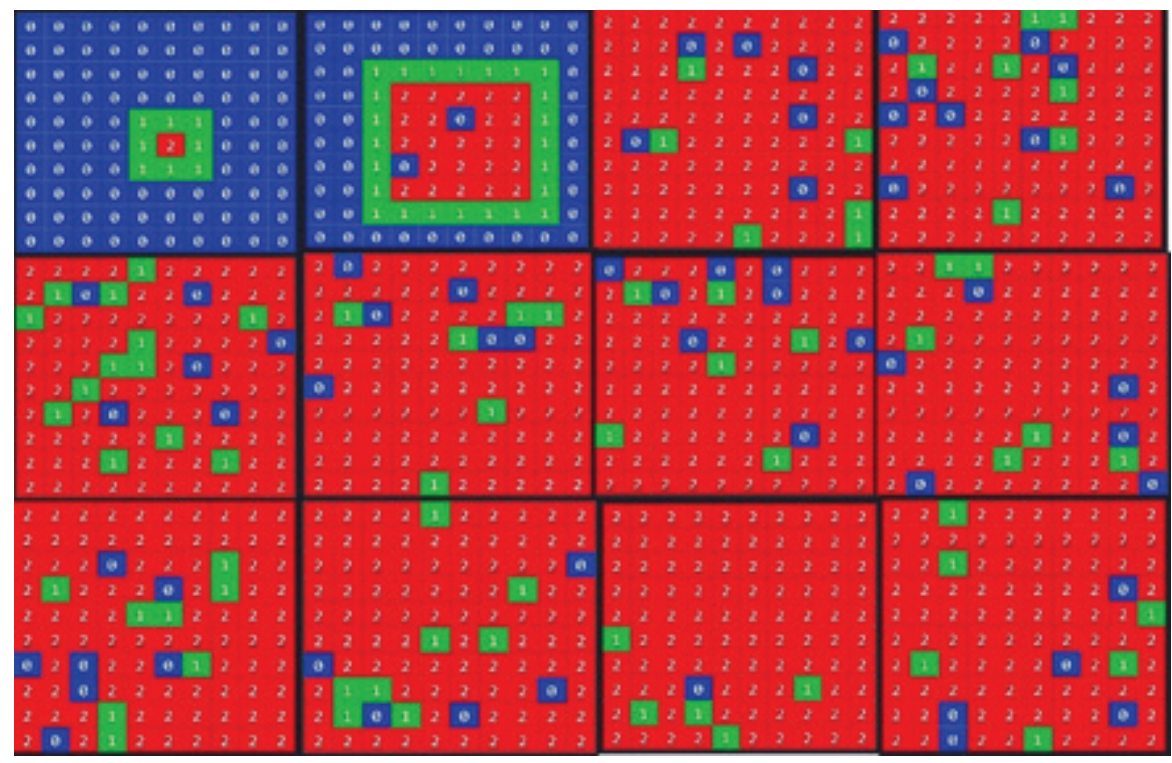

Gráfico $N^{\circ}$ 8. Filtración de Escenario $\mathrm{N}^{\circ} 1$

Fuente: Elaboración propia. 
En el primer cuadro se presenta el estado inicial, amante al riesgo, donde hay una población de agentes con portafolio de activos riesgosos (0). Un agente vende su portafolio (2) y a raíz de la probabilidad de contagio $p_{i j}=1$, ocho agentes vecinos se encuentran en evaluación de cambio (1).

El resto de los cuadros muestran el efecto contagio, y la velocidad con que se produce esto depende de la probabilidad de contagio. El cuadro final es el estado final, averso al riesgo, donde aproximadamente el $90 \%$ de los inversionistas vendieron su portafolio. El siguiente gráfico se presenta la filtración de estos cambios de estado.

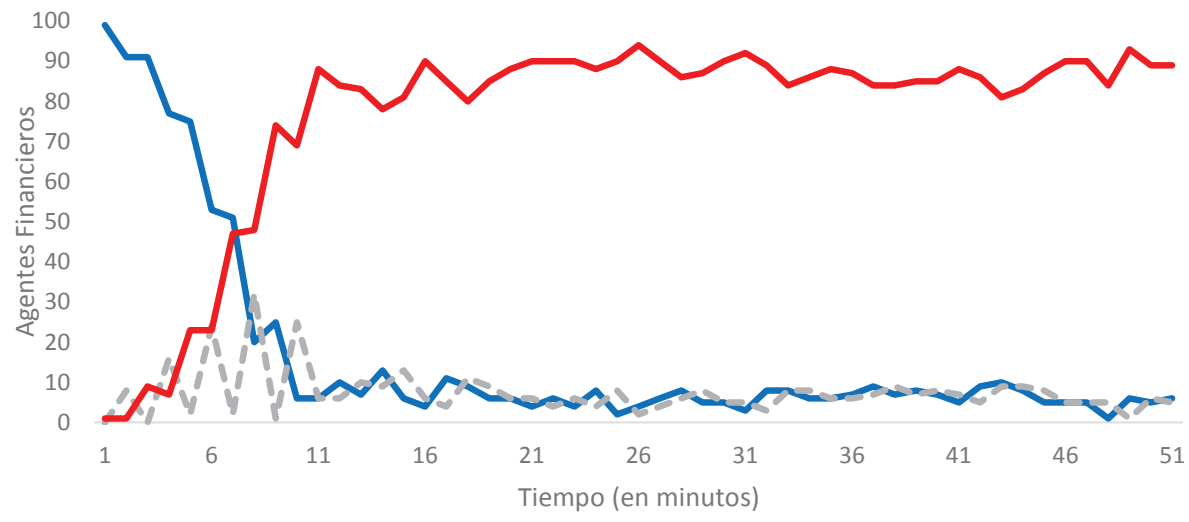

Con Acciones (amante al riesgo) - Evaluación de Cambio Sin Acciones (averso al riesgo)

Gráfico $N^{\circ}$ 9. Filtración de los Estados bajo el Escenario $\mathrm{N}^{\circ} 1$ (probabilidad de contagio pij=1)

Fuente: Elaboración propia.

En el estado inicial, amante al riesgo, los agentes financieros parten con un portafolio de activos financieros riesgosos (acciones) y dado una probabilidad de contagio $p_{i j}=1$, en los primeros siete minutos se produce el cambio de estado y a partir del minuto 10 aproximadamente el $90 \%$ de los inversionistas venden todo su portafolio de activos riesgosos y se refugian en activos seguros (bonos), llegando así al estado de averso al riesgo. Los inversionistas que se quedan en el escenario anterior de amante al riesgo y en expectativa de cambio representan alrededor del $10 \%$ en total, aproximadamente $5 \%$ cada uno. 


\subsubsection{Estado final: escenario de simulación 2}

En el segundo escenario de la simulación computacional se considera una probabilidad de contagio de $90 \%$. Al realizar la simulación computacional en Cell-DEVS se obtendrá un historial de estados de los agentes financiero dentro de tiempo considerado.

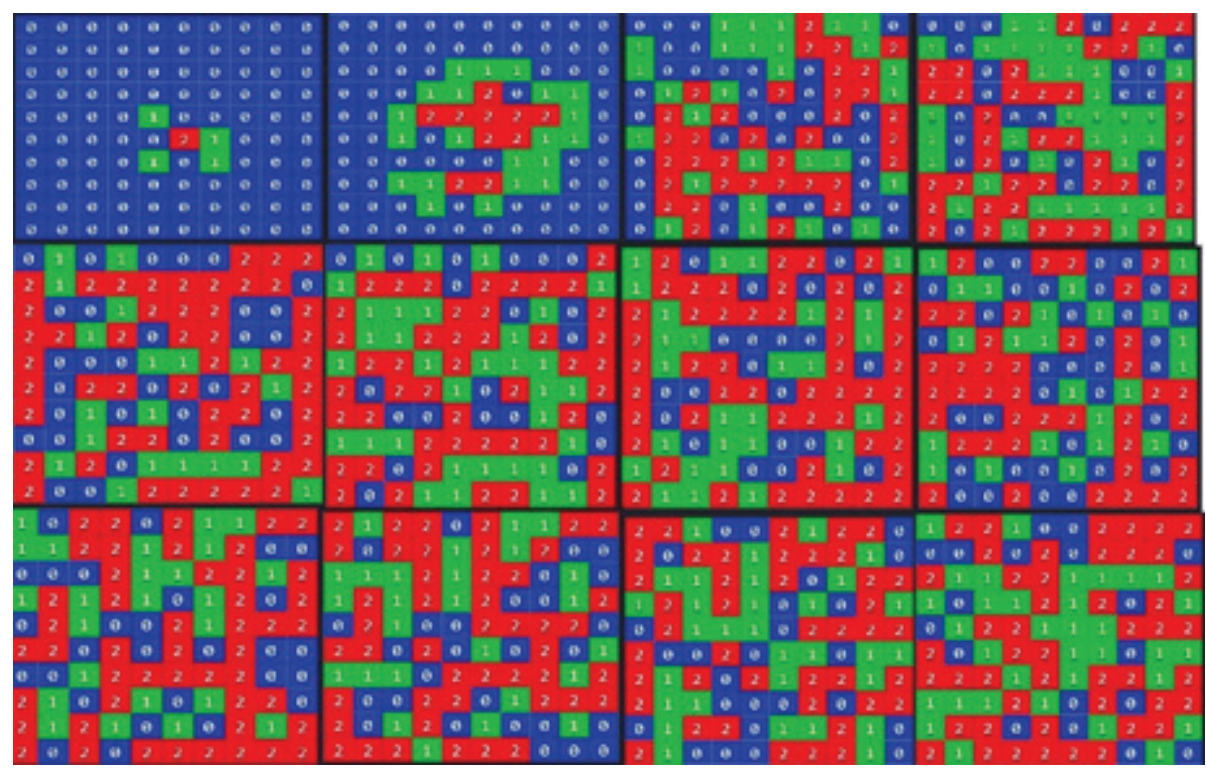

Gráfico $N^{\circ} 10$. Filtración de Escenario $\mathrm{N}^{\circ} 2$

Fuente: Elaboración propia.

En el primer cuadro se presenta el estado inicial, amante al riesgo, donde hay una población de agentes con portafolio de activos riesgosos (0). Un agente vende su portafolio (2) y a raíz de la probabilidad de contagio $p_{i j}=0.9$, cuatro agentes vecinos se encuentran en evaluación de cambio (1). El resto de los cuadros muestran el efecto contagio, y la velocidad con que se produce esto depende de la probabilidad de contagio.

El cuadro final es el estado final, averso al riesgo, donde aproximadamente el $50 \%$ de los inversionistas vendieron su portafolio. El siguiente gráfico se presenta la filtración de estos cambios de estado. De la simulación se puede obtener la siguiente historia de cada estado. 


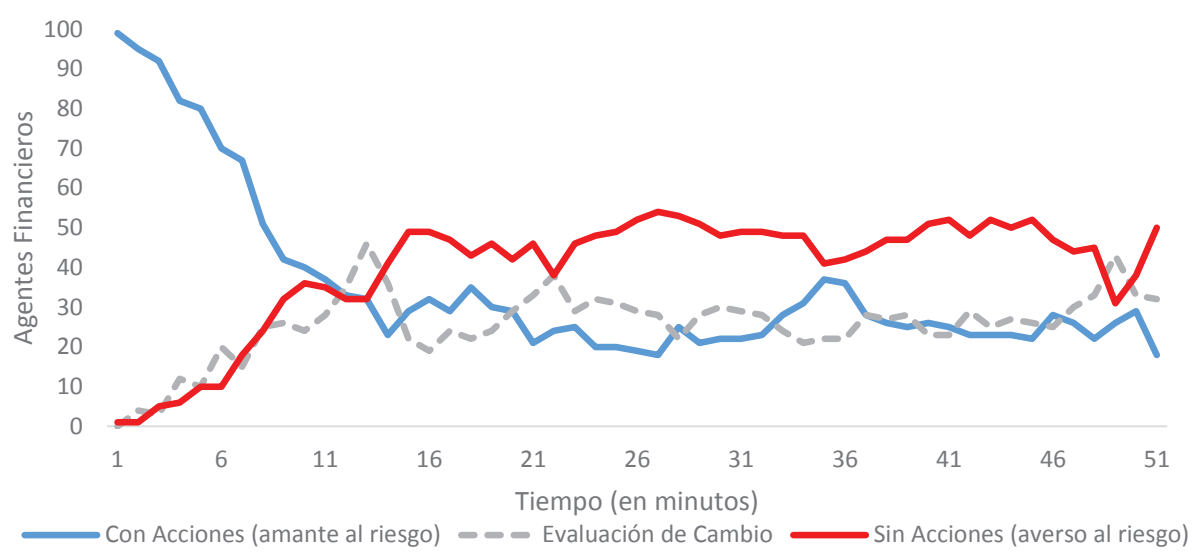

Gráfico $N^{\circ} 11$. Filtración de los Estados bajo el Escenario $\mathrm{N}^{\circ} 2$

(probabilidad de contagio pij=0.9)

Fuente: Elaboración propia.

En el estado inicial, amante al riesgo, los agentes financieros parten con un portafolio de activos financieros riesgosos (acciones) y dado una probabilidad de contagio $p_{i j}=0.9$, en los primeros doce minutos se produce el cambio de estado y a partir del minuto 15 aproximadamente el 50\% de los inversionistas venden todo su portafolio de activos riesgosos y se refugian en activos seguros (bonos), llegando así al estado de averso al riesgo. Los inversionistas que se quedan en el escenario anterior de amante al riesgo y en expectativa de cambio representan alrededor del $50 \%$; aproximadamente $18 \%$ y $32 \%$, respectivamente.

\subsubsection{Estado final: escenario de simulación 3}

En el tercer escenario de la simulación computacional se una probabilidad de contagio de 50\%.En este escenario se ha considerado una probabilidad más equilibrada debido que las decisiones se tienen una variabilidad de una manera más pausada donde la interacción del medio influye en gran medida y como la percepción de los inversionistas reacciona.

En el estado inicial, amante al riesgo, los agentes financieros parten con un portafolio de activos financieros riesgosos (acciones) y dado una 
probabilidad de contagio $p_{i j}=0.9$, en los primeros doce minutos se produce el cambio de estado y a partir del minuto 15 aproximadamente el 50\% de los inversionistas venden todo su portafolio de activos riesgosos y se refugian en activos seguros (bonos), llegando así al estado de averso al riesgo. Los inversionistas que se quedan en el escenario anterior de amante al riesgo y en expectativa de cambio representan alrededor del 50\%; aproximadamente 18\% y 32\%, respectivamente. De la simulación se puede obtener la siguiente historia de cada estado.

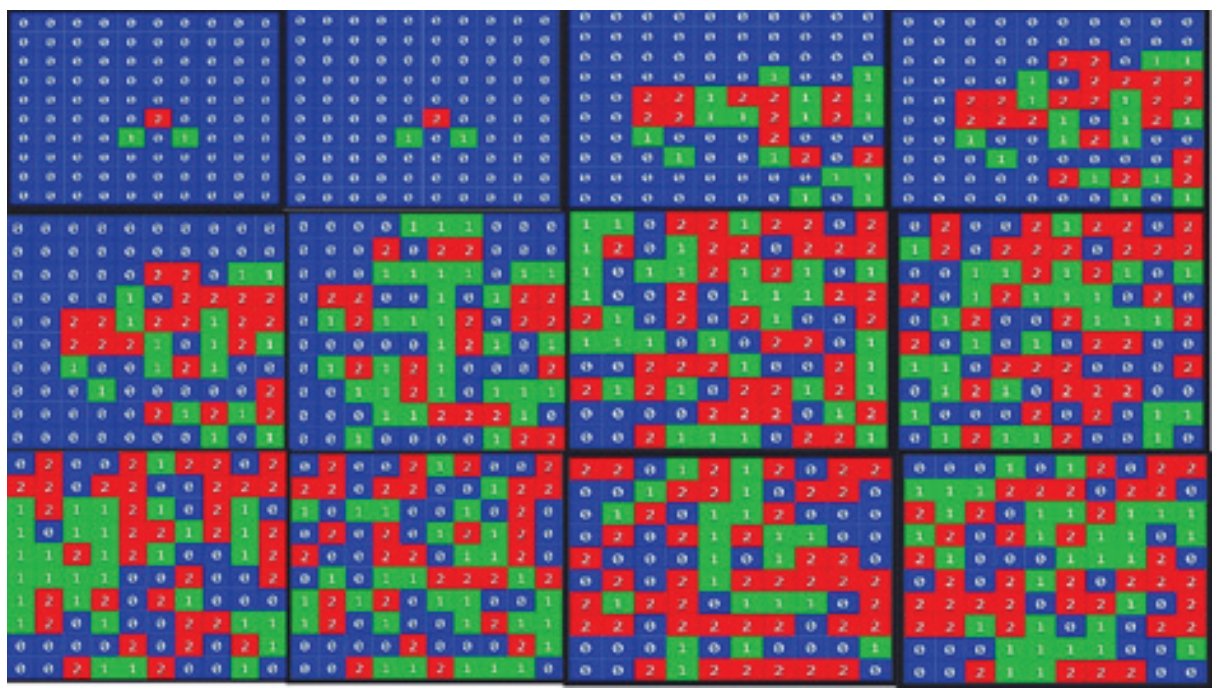

Gráfico $N^{\circ} 12$. Filtración de Escenario $\mathrm{N}^{\circ} 3$

Fuente: Elaboración propia.

En el estado inicial, amante al riesgo, los agentes financieros parten con un portafolio de activos financieros riesgosos (acciones) y dado una probabilidad de contagio $p_{i j}=0.5$, en los primeros doce minutos se produce el cambio de estado y a partir del minuto 25 aproximadamente el 38\% de los inversionistas venden todo su portafolio de activos riesgosos y se refugian en activos seguros (bonos), llegando así al estado de averso al riesgo. Los inversionistas que se quedan en el escenario anterior de amante al riesgo y en expectativa de cambio representan alrededor del $60 \%$; aproximadamente $35 \%$ y $25 \%$, respectivamente. 


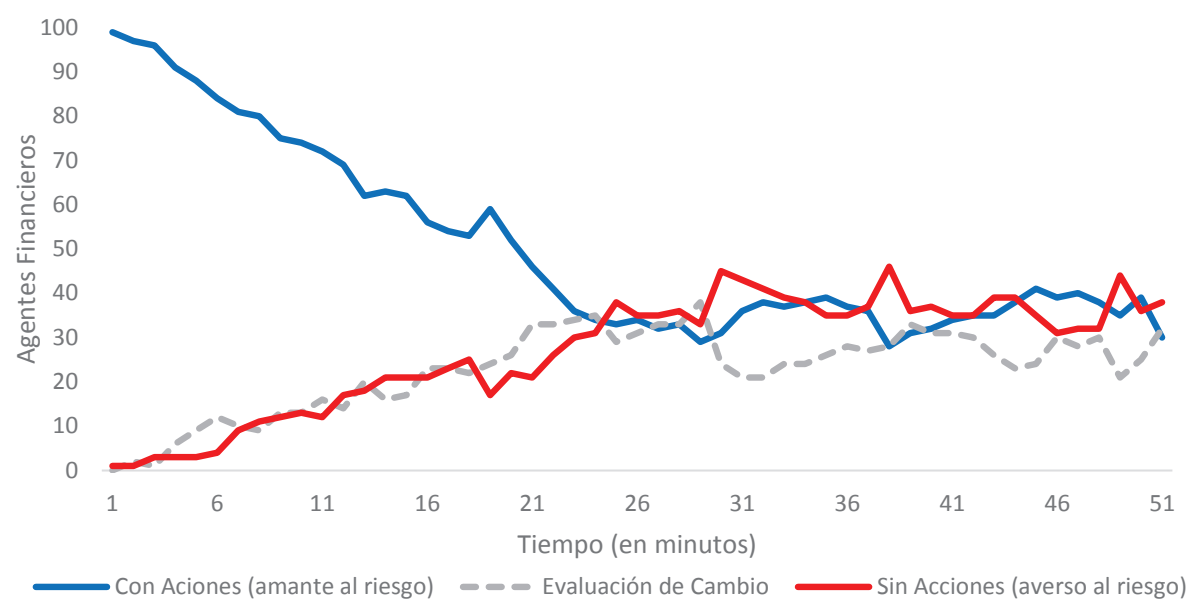

Gráfico $N^{\circ} 13$. Filtración de los Estados bajo el Escenario $\mathrm{N}^{\circ} 3$

(probabilidad de contagio pij=0.5)

Fuente: Elaboración propia.

\subsubsection{Resumen de los escenarios de simulación}

A continuación, se hace un análisis comparativo de los resultados anteriores por estados del inversionista: amante y averso al riesgo. En el gráfico $\mathrm{N}^{\circ} 14$ se muestra el efecto contagioen el agente financiero que se encuentra en un estado amante al riesgo (poseedor de acciones), bajo distintas probabilidades de contagio: 100\%, 90\% y 50\%. Se puede apreciar que el número de agentes financieros poseedores de acciones disminuyen rápidamente en la medida que la probabilidad de contagio es alta.

Por otro lado, en el gráfico $\mathrm{N}^{\circ} 15$ se presenta el complemento del gráfico anterior. En la medida en que disminuye el número de agentes financieros poseedores de acciones (estado amante al riesgo) aumenta el número de agentes financieros poseedores de bonos (estado averso al riesgo). Cabe indicar que este cambio se produce rápidamente en la medida en que la probabilidad de contagio sea alta. 


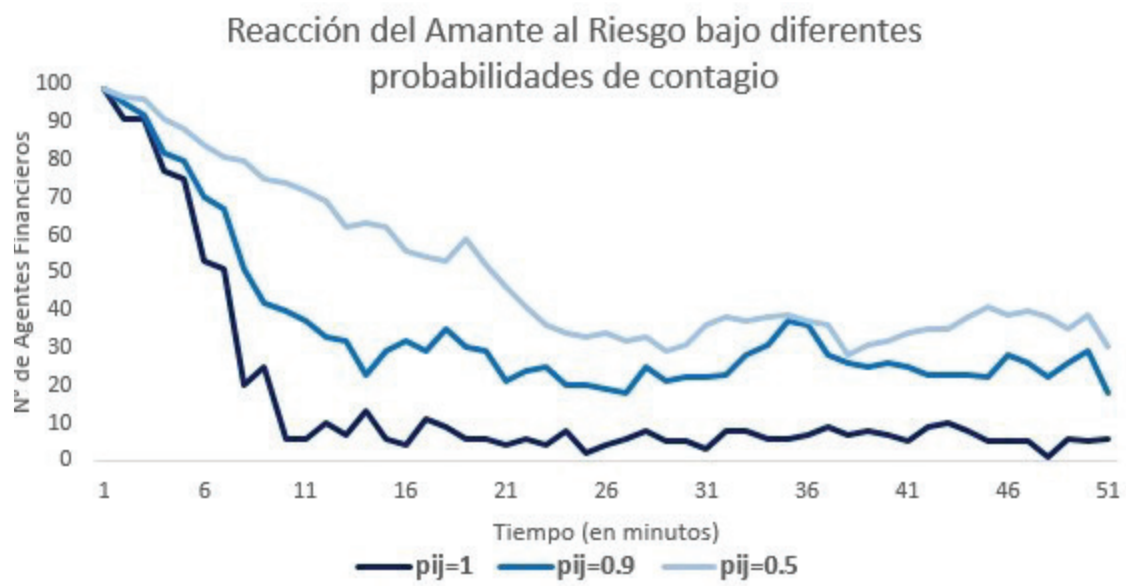

Gráfico $N^{\circ} 14$. Reacción del Amante al Riesgo bajo diferentes probabilidades de contagio

Fuente: Elaboración propia.

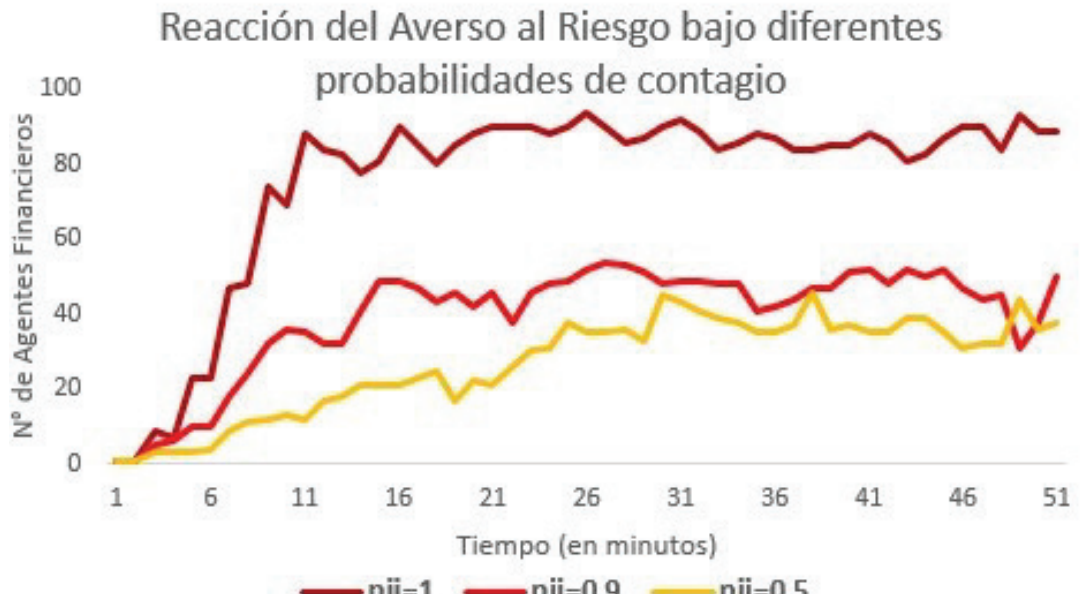

Gráfico $N^{\circ} 15$. Reacción del Averso al Riesgo bajo diferentes probabilidades de contagio

Fuente: Elaboración propia. 


\section{Conclusiones}

Después de presentar el modelo computacional tanto en el formalismo DEVS, y sus respectivas simulaciones computacionales en diferentes escenarios que se pueden dar en el medio del mercado, resaltamos lo siguiente:

- El fenómeno de interdependencia y contagio financiero puede ser simulado mediante un modelo computacional de autómatas Celulares en base a reglas sencillas.

- La dinámica de la interdependencia y la probabilidad del contagio para la simulación son resumidas en las reglas observables en el mercado financiero.

- Los resultados de la simulación muestran que la velocidad de cambio de los agentes financieros de un estado a otro depende de la probabilidad de contagio. Además, existe un número de agentes que se quedan en un estado Evaluación de Cambio debido a que no llegan a tomar su decisión de manera rápida.

- Los autómatas celulares permiten la apertura de un modelamiento computacional que puede complementarse con el modelamiento matemático (estocástico) para poder tener diferentes visiones de los fenómenos económicos sobre el contagio financiero.

- Las simulaciones computacionales mediante los autómatas celulares permiten una interpretación tiempo-espacio debido que se considera la interacción entre las células (agentes financieros) que están dentro del vecindario considerado.

- La epidemiologia matemática orientado a la dinámica de transmisión de enfermedades infecciosas podría ser un apoyo en el estudio de tiempo continuo para representar la dinámica del contagio financiero. 


\section{Referencias Bibliográficas}

Abramson, G. (2010). La matemática en las Epidemias. Centro Atómico Bariloche, Instituto Balseiro, CONICET. Argentina.

Anderson, R. M. (1982). Population Dynamics of Infectious Diseases: Theory and Applications. Chapman and Hall, London-New York.

Brauer, F. Castillo-Chávez, C. (2001). Mathematical Models in Population Biology and Epidemiology. NY: Springer.

Capasso, V. Serio, G. (1978). A generalization of the Kermack-McKendrick deterministic epidemic model. Mathematical Biosciences, 42(1-2), 43-61.

Capinski, Marek. Zastawniak, Tomasz. (2003). Mathematics for Finance. An Introduction to Financial Engineering. Springer.

Dirección General de Epidemiología. (2015). Nociones Básicas de Modelamiento Matemático a la Epidemiologia. Ministerio de Salud.

Dirección General de Epidemiología. (2017). Boletín Epidemiológico del Perú. Vol. 26. SE. 12. Centro Nacional de Epidemiología, Prevención y Control de Enfermedades. Ministerio de Salud.

Morales Noriega, Gladys V. (2015). Contagio Financiero e Interdependencia en América Latina: Análisis de Trasmisión de Shocks Financieros de Brasil hacia el Resto de los países Latinoamericanos. Universidad Complutense de Madrid. España.

Muñoz Reyes, Fabián Ricardo. (2013). Música con Autómatas Celulares. Universidad Nacional de Colombia. Bogotá, Colombia.

Parodi Trece, Carlos. (2017). La primera Crisis Financiera Internacional del siglo XXI. Fondo Editorial de la Universidad del Pacífico.

Pino Romero, Neisser. López Cruz, Roxana. L. Wainer, Gabriel. (2017). Modelamiento Computacional de la Dinámica de Transmisión de la Varicela mediante Autómatas Celulares (Cell-DEVS). Pesquimat, 20(2), 53-64.

Ratanov, Nikita (2009). Modelos Estocásticos de Mercados Financieros. Primera Edición. Editorial Universidad del Rosario. Bogotá, Colombia.

Toffoli, T. Margolus, N. (1987). Cellular automata machines: A new environment for modeling. Cambridge, MA: MIT Press.

Wainer, G., Giambiasi, N. (2002). N-dimensional Cell-Devs. Discrete Events Systems: Theory and Applications. 12:135-157. 
Wainer, Gabriel. (2009). Discrete Events Modelling and Simulation, A Practioner's Approach. CRC Press.

Wainer, Gabriel. (2009). Cellular Modelling with Cell-DEVS: A Discrete Event Cellular Automata Formalism. Carleton University. Canada.

Wilmott, Paul (2007). Introduces Quantitative Finance, Second Edition. John Wiley \& Sons, Ltd. London, UK.

Zeigler Bernard. (1976). Theory of Modeling and Simulation. Society for Computer Simulation International, San Diego. (First Ed.). 